\title{
Spectroscopic Analysis of Au-Cu Alloy Nanoparticles of Various Compositions Synthesized by a Chemical Reduction Method
}

\author{
Latif-ur-Rahman, ${ }^{1}$ Afzal Shah, ${ }^{1}$ Rumana Qureshi, ${ }^{1}$ Sher Bahadar Khan, \\ Abdullah M. Asiri, ${ }^{2}$ Anwar-ul-Haq Ali Shah, ${ }^{3}$ Muhammad Ishaq, ${ }^{3}$ \\ Mohammad Saleem Khan, ${ }^{4}$ Suzanne Kay Lunsford, ${ }^{5}$ and Muhammad Abid Zia ${ }^{6}$ \\ ${ }^{1}$ Department of Chemistry, Quaid-i-Azam University, Islamabad 45320, Pakistan \\ ${ }^{2}$ Center of Excellence for Advanced Materials Research (CEAMR) and Chemistry Department, Faculty of Science, \\ King Abdulaziz University, P.O. Box 80203, Jeddah 21589, Saudi Arabia \\ ${ }^{3}$ Institute of Chemical Sciences, University of Peshawar, Peshawar, Khyber Pakhtunkhwa 25120, Pakistan \\ ${ }^{4}$ National Center of Excellence in Physical Chemistry, University of Peshawar, Peshawar, Khyber Pakhtunkhwa 25120, Pakistan \\ ${ }^{5}$ Wright State University, 3640 Colonel Glenn Highway, Dayton, OH 45435, USA \\ ${ }^{6}$ University of Education, Attock Campus, Attock 43600, Pakistan
}

Correspondence should be addressed to Afzal Shah; afzals_qau@yahoo.com

Received 10 December 2014; Accepted 11 March 2015

Academic Editor: Bin Li

Copyright (C) 2015 Latif-ur-Rahman et al. This is an open access article distributed under the Creative Commons Attribution License, which permits unrestricted use, distribution, and reproduction in any medium, provided the original work is properly cited.

\begin{abstract}
$\mathrm{Au}-\mathrm{Cu}$ alloy nanoparticles were synthesized by a chemical reduction method. Five samples having different compositions of Au and $\mathrm{Cu}(\mathrm{Au}-\mathrm{Cu} 3: 1, \mathrm{Au}-\mathrm{Cu} 2: 1, \mathrm{Au}-\mathrm{Cu} 1: 1, \mathrm{Au}-\mathrm{Cu} 1: 2$, and $\mathrm{Au}-\mathrm{Cu} 1: 3)$ were prepared. The newly synthesized nanoparticles were characterized by electronic absorption, fluorescence, and X-ray diffraction spectroscopy (XRD). These alloy nanoparticles were also analyzed by SEM and TEM. The particle size was determined by SEM and TEM and calculated by Debye Scherrer's equation as well. The results revealed that the average diameter of nanoparticles gets lowered from 80 to $65 \mathrm{~nm}$ as the amount of Cu is increased in alloy nanoparticles. Some physical properties were found to change with change in molar composition of Au and $\mathrm{Cu}$. Most of the properties showed optimum values for $\mathrm{Au}-\mathrm{Cu}$ alloy nanoparticles of 1:3. $\mathrm{Cu}$ in $\mathrm{Au}$-Cu alloy caused decrease in the intensity of the emission peak and acted as a quencher. The fluorescence data was utilized for the evaluation of number of binding sites, total number of atoms in alloy nanoparticle, binding constant, and free energy of binding while morphology was deduced from SEM and TEM.
\end{abstract}

\section{Introduction}

The fascinating properties and small dimensions of bimetallic nanoparticles have sparked an intense research activity and nowadays "nanoscience" is one of the rapidly developing multidisciplinary fields. Nanoparticles find interesting research applications in the field of chemical engineering $[1,2]$. This is due to their unique catalytic, electrocatalytic, magnetic, optical, thermal, and electrical properties. Such properties of nanomaterials differ substantially from the typical properties of compact materials as quantum size effects come into play in particles of small dimensions. As particles size and shape play an important role in modifying the physical and chemical properties [3], so many efforts in nanostructural preparations have been focused to gain a control over the size and the shape of various types of nanoparticles [3]. Complete information about the size, shape, and structure of nanoparticles is essential prior to their applications in biomedical and other advanced fields [4].

With decrease in the size of nanoparticles, changes occur in geometrical, quantum, and statistical effects. Electronic properties are also related to quantum size effect. No such effect can be observed if the size particles are decreased from macro- to microlevels. However, quantum effects become dominant when size is further decreased to nanorange [4]. In such nanoparticles, nearly all the physical properties of 
TABLE 1: Details of the chemicals used.

\begin{tabular}{|c|c|c|c|c|c|}
\hline S. number & Compounds & Molecular mass/g & Solubility in ethylene glycol & Purity (\%) & Provider \\
\hline 1 & $\mathrm{HAuCl}_{4}$ & 265.5 & Soluble & 97.95 & Fluka \\
\hline 2 & $\mathrm{CuCl}_{2}$ & 134.5 & Soluble & 98.00 & Fluka \\
\hline 3 & PEI & 10000 & Soluble & 90.00 & Fluka \\
\hline
\end{tabular}

one of the metals are changed when its alloy is made with its partner metal. Bimetallic alloy nanoparticles may have random, core shell, cluster-in-cluster, and alloy structures. Random structures have no specific arrangement. In clusterin-cluster structures, heavy metals mostly make nanoclusters and the other light metals act as binders. However, such structures have no specific order [5]. The alloy structures of bimetallic alloy nanoparticles are more common. There are various types of alloy structures that depend on the size of the combining metals. The most common alloy structures are intermetallic alloy and random alloy. Ag-Au and Au$\mathrm{Cu}$ bimetallic alloy nanoparticles mostly form intermetallic alloy structures due to the differences in the size and binding abilities of $\mathrm{Ag}, \mathrm{Au}$, and $\mathrm{Cu}$.

Copper is the second metal having highest electrical conductivity [6]. However, a slight decrease in its electrical properties occurs when it captures oxygen because copper oxide is relatively lower in conductance than pure copper. Hence, copper cannot be found in metallic form due its higher tendency towards oxidation. During oxidation of copper, oxygen forms a coat around it, causing a decrease in its electrical conductivity. However, its bimetallic alloy nanoparticles can be prepared with Au which overcomes this problem. Although $\mathrm{Au}$ is expensive, only a small amount is the requirement of the developed method for the synthesis of $\mathrm{Au}-\mathrm{Cu}$ alloy nanoparticles. Au enhances the conductivity of copper to a greater extent and its bimetallic alloy nanoparticles can be used for the developing of an electrochemical sensor for the detection of polycyclic aromatic hydrocarbons.

Electrical performance of each of the $\mathrm{Au}$ and $\mathrm{Cu}$ metals can be improved by making their alloy [7]. This can be further improved by bringing their size on nanorange. Hence, $\mathrm{Au}-\mathrm{Cu}$ alloy nanoparticles have vast applications in the development of electrochemical and biosensors. Oxidation of $\mathrm{Au}$ and $\mathrm{Cu}$ can be prevented by making their alloy nanoparticles $[7,8]$. Loading nanoparticles at the surface region of polymer are of great interest due to their higher optical and potential applications $[9,10]$. Such nanoparticles embedded in silica glasses also improve optical properties [11]. All of these properties are related to the frequencies of surface plasmon resonance. The frequencies depend upon the ratios and composition of metallic nanoparticles. Hence, Au$\mathrm{Cu}$ bimetallic alloy nanoparticles with various compositions are manufactured.

Bimetallic alloy nanoparticles can be prepared by various methods. The most prominent methods are coprecipitation method and colloidal dispersion method using conducting polymer as capping agent. Many chemists have prepared the nanoparticles by chemical reduction methods [12, 13]. But most of the researchers have applied such methods for the preparation of colloidal mixture [14]. No doubt, these methods have synthetic applications but, for making nanoparticles of very small dimensions, these face serious difficulties. Hence, for the preparation of $\mathrm{Au}-\mathrm{Cu}$ alloy nanoparticles, chemical reduction is the simplest and least time consuming approach.

\section{Experimental}

2.1. Reagents and Apparatus. Copper chloride $\mathrm{CuCl}_{2}$ (98\%), hydrogen gold chloride $\mathrm{HAuCl}_{4}$ (99\%), ethylene glycol $\mathrm{C}_{2} \mathrm{H}_{6} \mathrm{O}_{2}(98 \%)$, and polyethyleneimine (2\%) were purchased from Thermo Fisher Scientific Inc. (USA). Polyethyleneimine was obtained from Acros Organics. For characterization centrifuge (6000 rmp/s) (model: PRO 300, Ginotech, China), UV spectrophotometer, steady-state fluorescence spectrophotometer, Perkin Elmer LS 55 (Cary 100, Varian, Shimadzu, Tokyo, Japan), XRD (Bruker, SMART APEX diffractometer), scanning electron microscopy (SEM) (Tecnai G2 F2O XTwin MAT), and TEM (Philips, Holand, Technai 20 model operating at $200 \mathrm{kV}$ ) were used.

\subsection{Synthesis of $A u$ and $C u$ Nanoparticles Using Chemical} Reduction Method. $10 \mathrm{~mL}$ of polyethyleneimine (2\%) was poured to $20 \mathrm{~mL}$ of hydrogen gold chloride $(1 \mathrm{mM})$ solution and heated at $100^{\circ} \mathrm{C}$ for 15 minutes. The appearance of yellowish black color evidenced the formation of $\mathrm{Au}$ nanoparticles that were confirmed by UV-Visible spectrophotometry. For preparation of $\mathrm{Cu}$ nanoparticles, $10 \mathrm{~mL}$ of polyethyleneimine (2\%) was added to $20 \mathrm{~mL}$ of copper chloride solution (1 mM). The mixture was purged with argon blow for 30 minutes. The solution was heated in oven at $175^{\circ} \mathrm{C}$ for 30 minutes. The appearance of bluish black color showed the formation of $\mathrm{Cu}$ nanoparticles which was ensured by electronic absorption spectroscopy. Both $\mathrm{Au}$ and $\mathrm{Cu}$ nanoparticles were stable for more than six months.

$\mathrm{Au}-\mathrm{Cu}$ bimetallic alloy nanoparticles were synthesized by taking $20 \mathrm{~mL}$ of polyethyleneimine (2\%) in $20 \mathrm{~mL}$ of hydrogen gold chloride $(1 \mathrm{mM})$ solution. $20 \mathrm{~mL}$ of copper chloride $(1 \mathrm{mM})$ was purged with argon blow and added. The whole sample was heated at $175^{\circ} \mathrm{C}$ for 15 minutes. The appearance of deep yellowish black color evidenced the synthesis of $\mathrm{Au}-\mathrm{Cu}$ nanoparticles which were ensured by electronic absorption spectroscopy. By changing molar ratios of both precursor salts, $\mathrm{Au}-\mathrm{Cu}$ alloy nanoparticles with various compositions, that is, $3: 1,2: 1,1: 1,1: 2$, and $1: 3$, were manufactured. Various chemicals along with their some important physical properties are mentioned in Table 1. While the chemicals and conditions required for the preparation of $\mathrm{Au}-\mathrm{Cu}$ alloy nanoparticles are listed in Table 2. 
TABLE 2: Chemicals and conditions required for preparation of various compositions of $\mathrm{Au}-\mathrm{Cu}$ alloy nanoparticles.

\begin{tabular}{lcccccc}
\hline S. number & Composition $\mathrm{Au}-\mathrm{Cu}$ & Volume $/ \mathrm{mL} \mathrm{HAuCl}$ & Volume $/ \mathrm{mL} \mathrm{CuCl}$ & $\mathrm{PEI} / \mathrm{mL}$ & $\mathrm{Purging} / \mathrm{min}$ & $\mathrm{Heating} 175^{\circ} \mathrm{C} / \mathrm{min}$ \\
\hline 1 & $3: 1$ & 15 & 5 & 10 & 25 & 15 \\
2 & $2: 1$ & 10 & 5 & 5 & 30 & 20 \\
3 & $1: 1$ & 5 & 5 & 5 & 45 & 25 \\
4 & $1: 2$ & 5 & 10 & 8 & 10 & 60 \\
5
\end{tabular}

\section{Results and Discussion}

$\mathrm{Au}, \mathrm{Cu}$, and $\mathrm{Au}-\mathrm{Cu}$ alloy nanoparticles were synthesized. Different samples of $\mathrm{Au}-\mathrm{Cu}$ alloy nanoparticles were synthesized by changing molar ratios of $\mathrm{Au}$ and $\mathrm{Cu}$ salt precursors. These were characterized by UV-Visible spectroscopy, SEM, TEM, $\mathrm{XRD}$, and fluorescence spectroscopy.

3.1. UV-Visible Spectroscopy. Figures 1 and 2 show the UVVisible spectra of $\mathrm{Au}$ and $\mathrm{Cu}$ nanoparticles. The spectra show maximum absorption at 455 and $558 \mathrm{~nm}$ for pure $\mathrm{Au}$ and $\mathrm{Cu}$ nanoparticles, respectively. These values are closely related to the literature reported values (i.e., $\lambda_{\max }$ at 495 and $555 \mathrm{~nm}$ for $\mathrm{Au}$ and $\mathrm{Cu}$, resp.) [15]. UV-Visible spectra of $\mathrm{Au}-\mathrm{Cu}$ with various compositions of $\mathrm{Au}$ and $\mathrm{Cu}$ can also be seen in Figure 3. Such spectra show peaks having $\lambda_{\max }$ at the mid of pure $\mathrm{Au}$ and $\mathrm{Cu}$ nanoparticles. Figure 3 shows a bathochromic shift in maximum wavelength with increase in composition of $\mathrm{Cu}$ in $\mathrm{Au}-\mathrm{Cu}$. It also supports the confirmation evidences of $\mathrm{Au}-\mathrm{Cu}$ alloy nanoparticles formation. The $\lambda_{\max }$ values of all the samples have been tabulated in Table 3. Molar extinction coefficient, $\varepsilon$, was calculated for all the samples by recording their spectra at various concentrations. By applying BeerLambert law, molar extinction coefficient was calculated from the plot of absorbance versus concentration according to

$$
A=\varepsilon c l,
$$

where $A$ is absorbance, $\varepsilon$ the molar extinction coefficient in $\mathrm{M}^{-1} \mathrm{~cm}^{-1}$, and $c$ the concentration in $\mathrm{mol} / \mathrm{dm}^{3}$ while $l$ is the path length in $\mathrm{cm}$. The plot showing change in slope (molar absorptivity coefficient) can be seen in Figure 4 . The surface plasmon absorption band shows bathochromic shift with increasing composition of $\mathrm{Cu}$ as witnessed by the appearance of bluish color [16]. The appearance of single absorption peak also confirms that nanoparticles are not physically mixed nanoparticles but they have alloy structure. If they were not alloy structure, they would have shown two plasmon bands [17].

An examination of Table 3 reveals that absorbance and molar absorption coefficient get lowered with increase in composition of $\mathrm{Cu}$ in $\mathrm{Au}-\mathrm{Cu}$ alloy. The table also reveals red shift in $\lambda_{\max }$ with elevation of $\mathrm{Cu}$. The bathochromic shift is due to change in the particle size as well as some important variation in the refractive index occurring in the medium [17]. By plotting $\lambda_{\max }$ of pure $\mathrm{Au}$, samples $\mathrm{Au}-\mathrm{Cu} 3: 1, \mathrm{Au}-$ $\mathrm{Cu} 2: 1, \mathrm{Au}-\mathrm{Cu} 1: 1, \mathrm{Au}-\mathrm{Cu} 1: 2$, and $\mathrm{Au}-\mathrm{Cu} 1: 3$, and pure $\mathrm{Cu}$ nanoparticles versus mole fraction of $\mathrm{Cu}$, a linear relationship as shown in Figure 5 was obtained. Hence, $\lambda_{\max }$ value gets increased by the increase in mole fraction of $\mathrm{Cu}[18,19]$.

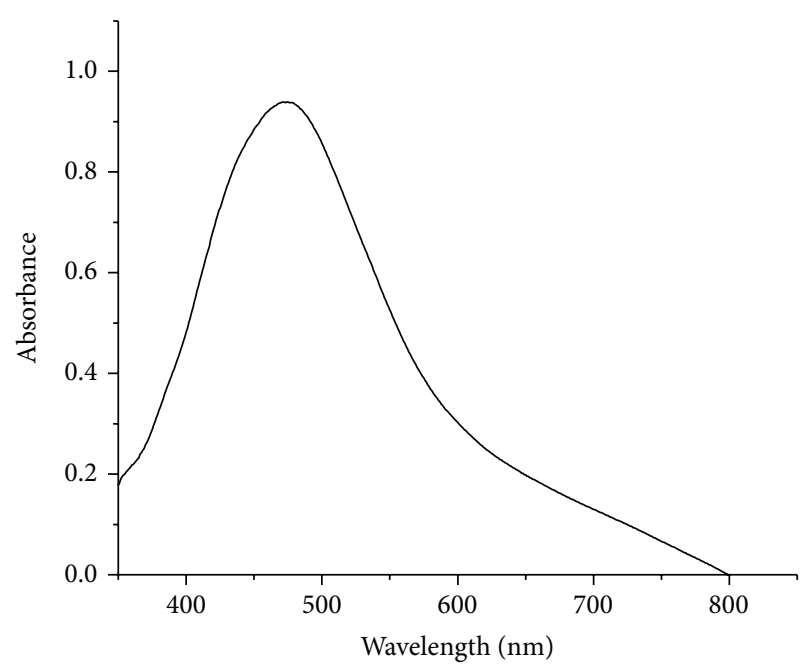

FIGURE 1: UV-Visible spectrum of Au nanoparticles, using ethylene glycol as a solvent as well as a reducing agent at temperature of $298 \mathrm{~K}$.

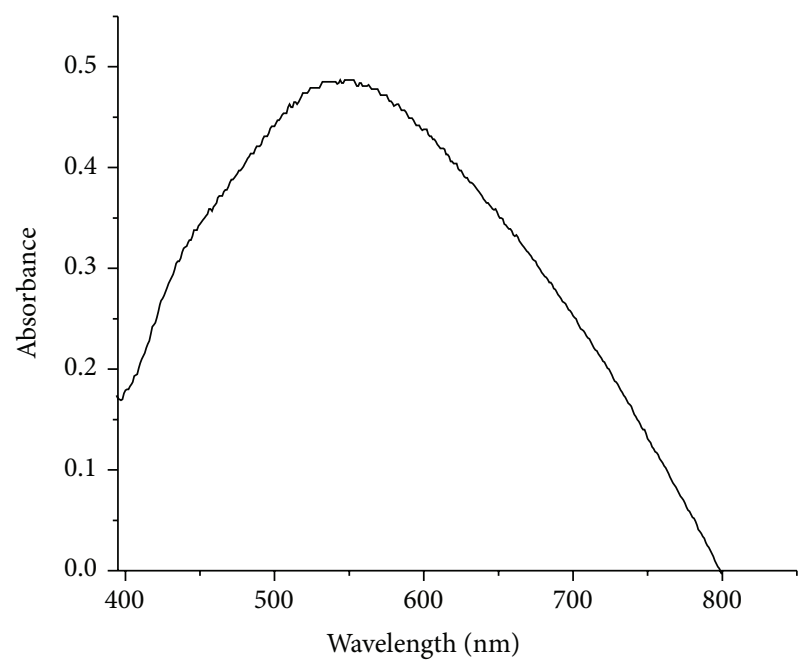

FIgURE 2: UV-Visible spectrum of $\mathrm{Cu}$ nanoparticles taken at $398 \mathrm{~K}$, using ethylene glycol as a solvent as well as a reducing agent.

3.2. Fluorescence Spectroscopy. Fluorescence signals of copper and gold nanoparticles appear at 645 and $530 \mathrm{~nm}$, respectively $[5,20]$. Fluorescence signals shown by $\mathrm{Au}-\mathrm{Cu}$ bimetallic alloy nanoparticles are in the mid-range of pure gold and copper nanoparticles. The basic concept for the fluorescence of Au involves the transition of electrons from its $\mathrm{d}$ orbital to excited electronic states in the sp-band [21]. In a similar way, 
TABLE 3: UV-Visible spectral characteristics of Au-Cu alloy nanoparticles in different ratios.

\begin{tabular}{|c|c|c|c|c|c|c|}
\hline S. number & $\mathrm{Au}: \mathrm{Cu}$ & $X$ of $\mathrm{Au}$ & $X$ of $\mathrm{Cu}$ & Absorbance & $\in / \mathrm{M}^{-1} \mathrm{~cm}^{-1}$ & $\lambda_{\max } / \mathrm{nm}$ \\
\hline 1 & $3: 1$ & 0.7 & 0.25 & 0.93 & 284.23 & 490 \\
\hline 2 & $2: 1$ & 0.6 & 0.33 & 0.85 & 220.53 & 495 \\
\hline 3 & $1: 1$ & 0.5 & 0.5 & 0.65 & 186.66 & 500 \\
\hline 4 & $1: 2$ & 0.4 & 0.6 & 0.5 & 143.68 & 530 \\
\hline 5 & $1: 3$ & 0.3 & 0.7 & 0.33 & 116.89 & 555 \\
\hline
\end{tabular}

TABLE 4: Parameters obtained from fluorescence spectroscopy.

\begin{tabular}{lcccccccc}
\hline S. number & $\mathrm{Au}: \mathrm{Cu}$ & $I_{0}$ & $I_{\mathrm{Q}}$ & $\lambda_{\max } / \mathrm{nm}$ & Number of atoms $(n)$ & Binding sites & Binding constant & $\Delta G_{b} /(\mathrm{KJ} / \mathrm{mol})$ \\
\hline 1 & $3: 1$ & 320 & 250 & 558 & 350 & 0.19 & 7.89 & -3.30 \\
2 & $2: 1$ & 320 & 235 & 559 & 425 & 0.33 & 24.60 & -5.40 \\
3 & $1: 1$ & 320 & 225 & 560 & 485 & 0.56 & 0.65 & 115.5 \\
4 & $1: 2$ & 320 & 215 & 560 & 505 & 0.72 & 180.3 & -15.50 \\
5 & $1: 3$ & 320 & 200 & 560 & 530 & & -20.25 \\
\hline
\end{tabular}

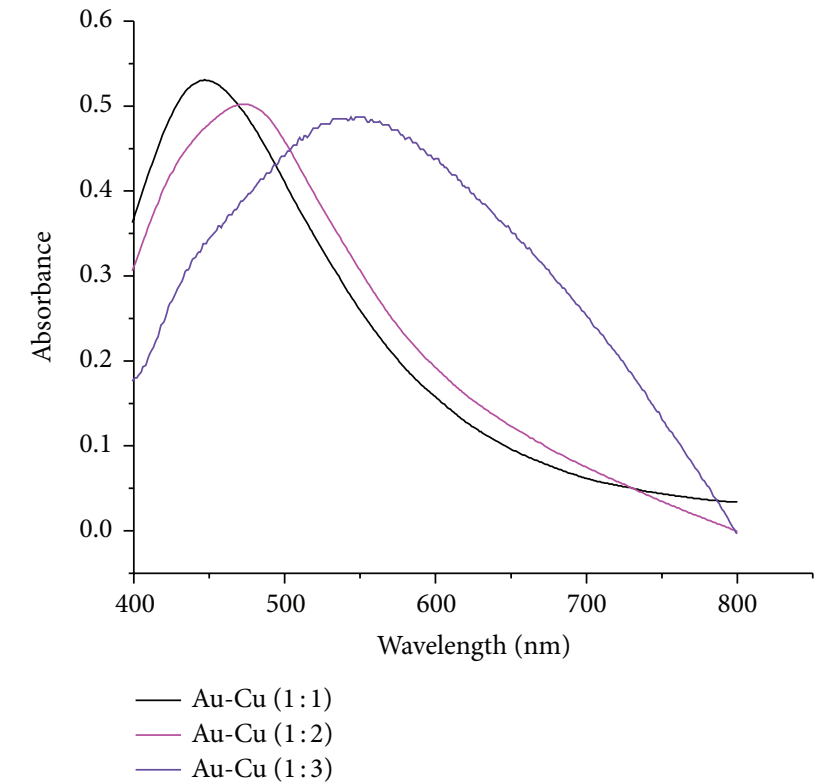

Figure 3: UV-Visible spectra of $\mathrm{Au}-\mathrm{Cu}(1: 1), \mathrm{Au}-\mathrm{Cu}(1: 2)$, and $\mathrm{Au}-$ $\mathrm{Cu}(1: 3)$ nanoparticles showing bathochromic shift with increase in composition of $\mathrm{Cu}$ in $\mathrm{Au}-\mathrm{Cu}$ alloy nanoparticles.

emission spectrum of $\mathrm{Cu}$ is due to deexcitation of electron from excited states to d orbital. Physically mixed solutions of gold and copper nanoparticles give two distinct emission spectra but their alloy nanoparticles register a single emission peak as expected. Confirmation of the synthetic process as revealed by single absorption spectrum is also supported by the appearance of single emission signal as shown in Figure 6, for the alloys nanoparticles with varying copper content. Figure 6 shows that $\mathrm{Cu}$ acts as quencher, because an increase in its composition in $\mathrm{Au}-\mathrm{Cu}$ nanoparticles causes decrease in its intensity. The emission $\lambda_{\max }$ for fluorescence is higher than absorption $\lambda_{\max }$ as expected [22]. Tabulated data from fluorescence spectroscopy demonstrates a blue shift in $\lambda_{\max }$

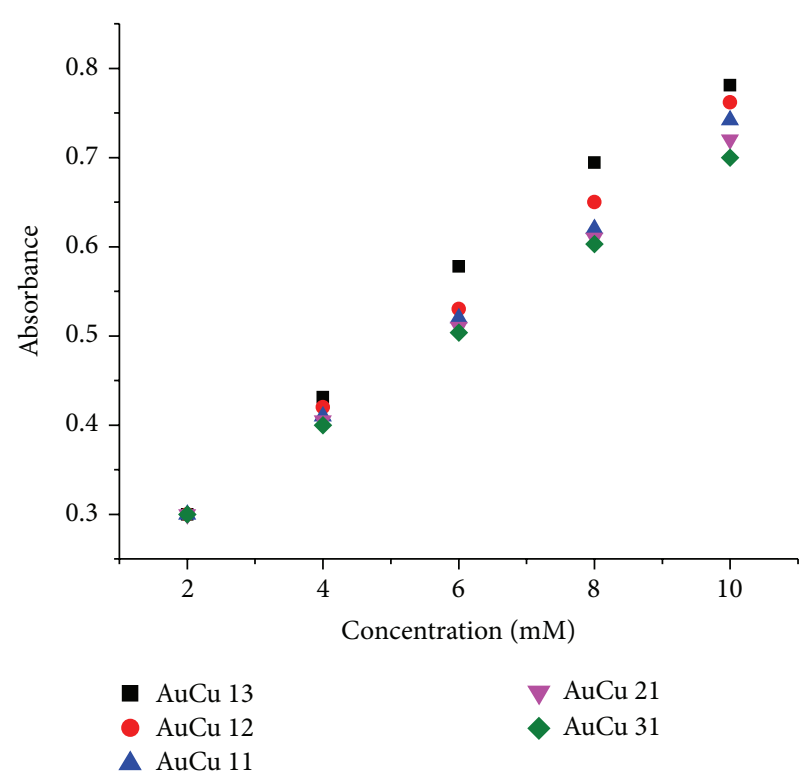

FIgURE 4: Plots of absorbance versus concentration for $\mathrm{Au}-\mathrm{Cu}$.

and hypochromic effect in the intensity from $\mathrm{Au}-\mathrm{Cu} 3: 1$ to $\mathrm{Au}-\mathrm{Cu} 1: 1$, but that from $\mathrm{Au}-\mathrm{Cu} 1: 1$ to $\mathrm{Au}-\mathrm{Cu} 1: 3$ remains the same as shown in Table 4 . An equation showing relation between relative intensity and concentration of the quencher to sample is given here:

$$
\log \frac{I_{0}}{I_{Q}}=\frac{[Q] N}{[X]}
$$

where $I_{Q}$ and $I_{0}$ represent the intensity with and without quencher, $[Q]$ is the concentration of quencher, $[X]$ is the concentration of sample in $\mathrm{mM}$, and $N$ is the number of atoms in nanoparticles. Plotting $\log I_{0} / I_{Q}$ versus $[Q] /[X]$, using (2), number of atoms, $N$, can be determined from the slope. 


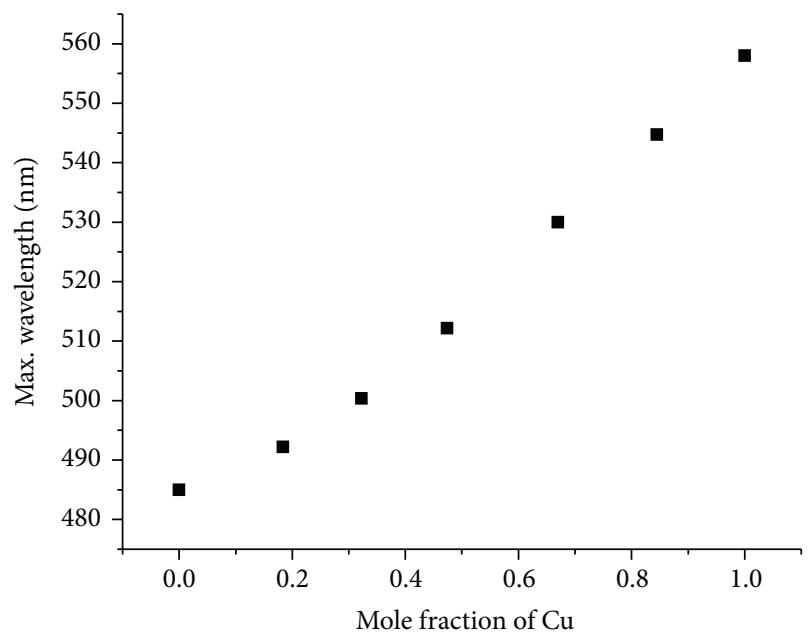

Figure 5: Plot of Max. wavelength versus mole fraction of $\mathrm{Cu}$ in $\mathrm{Au}-$ $\mathrm{Cu}$ alloy nanoparticles.

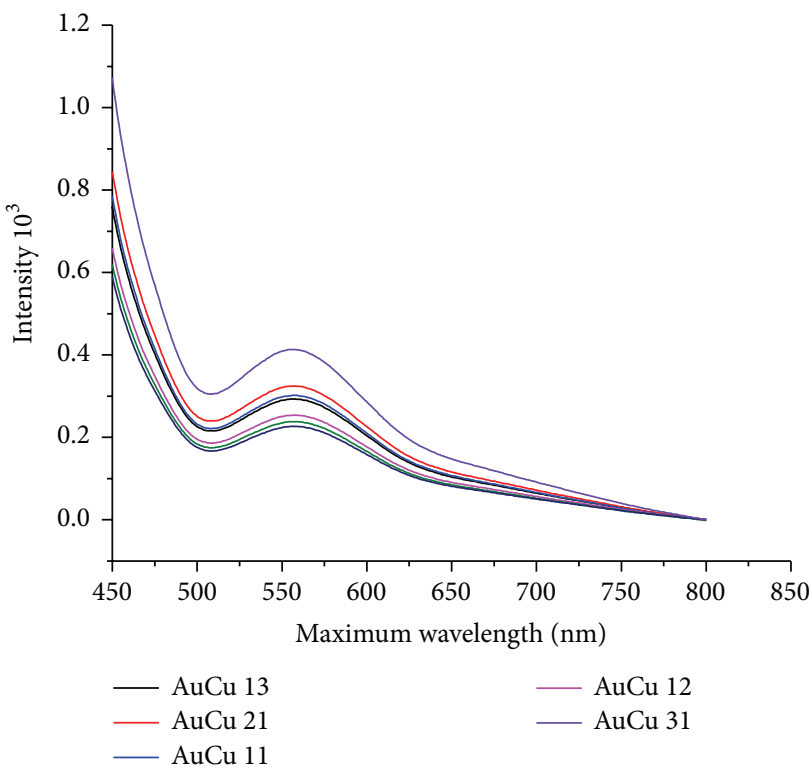

FIGURE 6: Fluorescence accumulative spectra of $\mathrm{Au}-\mathrm{Cu}$ alloy nanoparticles.

Similarly, another relation showing relative change in the intensity $\left(\log I_{0}-I_{\mathrm{Q}} / I_{\mathrm{Q}}\right)$, binding constant $\left(k_{b}\right)$, and quencher concentration can be represented as

$$
\log \frac{I_{0}-I_{Q}}{I_{Q}}=\log k_{b}+n \log [Q]
$$

Binding constant and binding sites can be evaluated from the intercept and slope of the plot of $\log \left(I_{0}-I_{Q} / I_{Q}\right)$ as a function of $\log [Q]$. Number of binding sites, $n$, and binding constant, $k_{b}$, were found to increase with the increase in the amount of $\mathrm{Cu}$ as shown in Table 4.

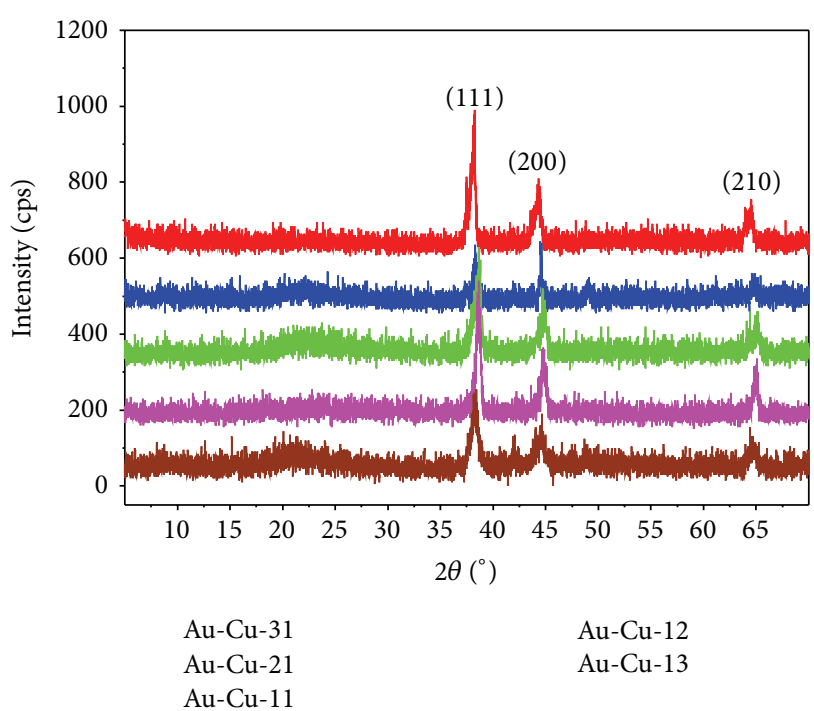

Figure 7: XRD spectra for samples Au-Cu 3:1, Au-Cu 2:1, Au-Cu $1: 1, \mathrm{Au}-\mathrm{Cu} 1: 2$, and $\mathrm{Au}-\mathrm{Cu} 1: 3$.

To study spontaneity of the aggregation, Gibb's free energy relating to binding constant is given as

$$
\Delta G_{b}=R T \ln k_{b} .
$$

In order to know whether the process is spontaneous or nonspontaneous, free energy of binding was calculated from (4). Variations in the intensity as evidenced by Figure 6 can be attributed to the crystal structures [23]. Table 4 shows data obtained from fluorescence spectroscopy. The number of atoms, $N$, increases with increase in composition of $\mathrm{Cu}$ due to its comparatively smaller atomic radius. The values of $n$ and $k_{b}$ and $\Delta G_{b}$ also increase with increasing $\mathrm{Cu}$ content. Hence, increasing amount of $\mathrm{Cu}$ in $\mathrm{Au}-\mathrm{Cu}$ makes the process more spontaneous as revealed by negative values of $\Delta G_{b}$.

3.3. X-Ray Diffraction Spectroscopy (XRD). For the study and evaluation of some important parameters like composition studies and calculation of average diameter of the nanoparticles, the combined XRD spectra were recorded for all the prepared samples. XRD results revealed that upon addition of one element in the matrix of the other a shift in the signal occurs as observable from the shift of Au signal due to continuous addition of $\mathrm{Cu}$ in $\mathrm{Au}$ matrixes [24]. Three peaks, that is, (111), (200), and (210), can be seen in the spectra shown in Figure 7.

Using XRD, different lattice points exposed in crystallite were determined. Possible crystal structure was determined from XRD analysis. Figure 7 shows that two distinct peaks, that is, (111) at 32 and (200) at 37, are more intense and show more exposure of the lattice points at these positions. These signals were considered the desired peaks for calculation of the size of nanoparticles. Hence, average diameter of all the nanoparticles was calculated by using Debye Scherrer formula as shown in (5). The $2 \theta$ of the XRD signal moves positively with increasing mole fraction of $\mathrm{Cu}$, due to which size of the crystalloid gets retarded. Due to crystallite contraction, 


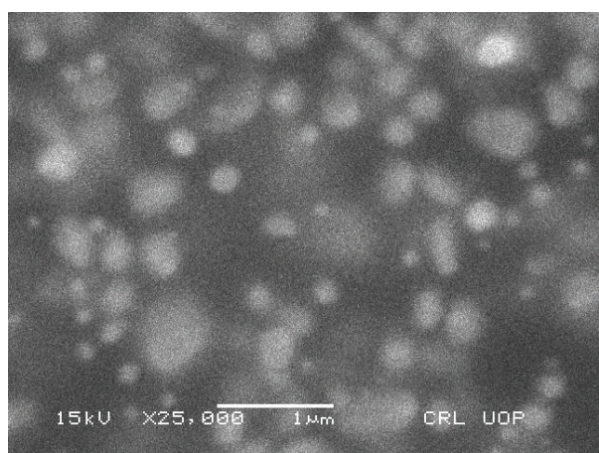

(a)

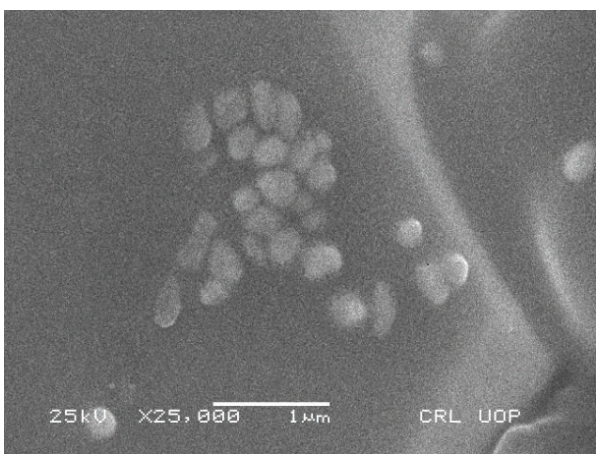

(c)

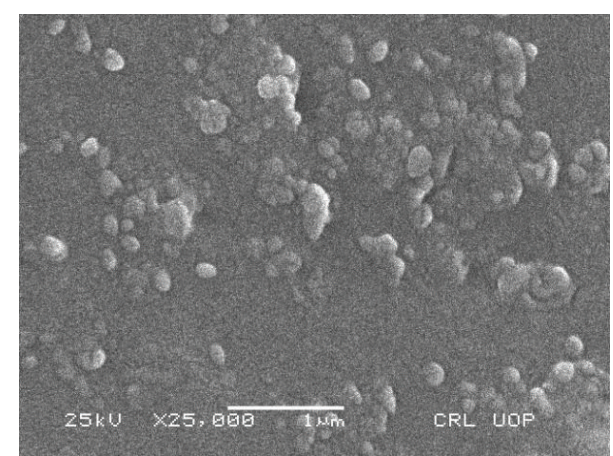

(b)

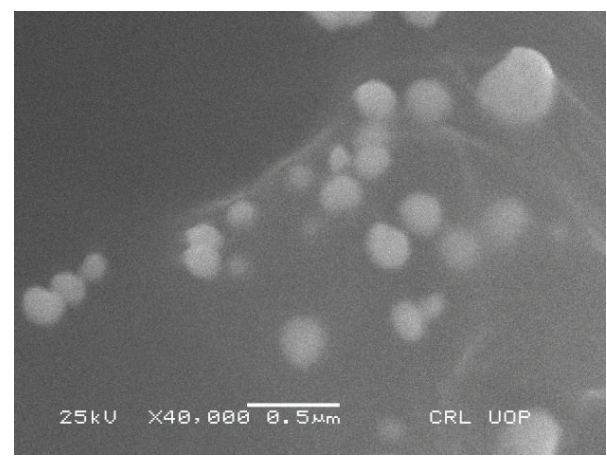

(d)

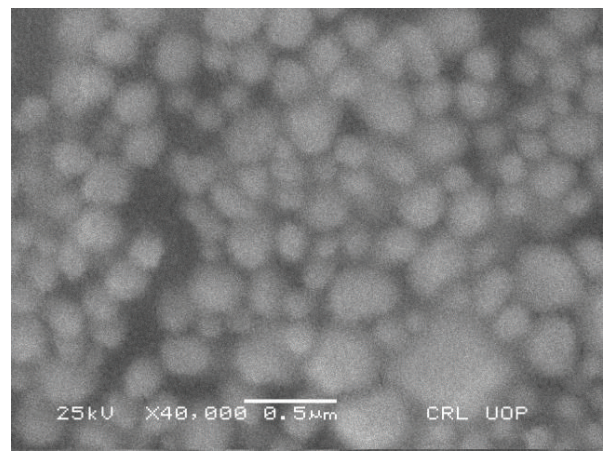

(e)

Figure 8: SEM images of (a) $\mathrm{Au},(\mathrm{b}) \mathrm{Cu},(\mathrm{c}) \mathrm{Au}-\mathrm{Cu}(1: 1)$, (d) $\mathrm{Au}-\mathrm{Cu}(1: 2)$, and (e) $\mathrm{Au}-\mathrm{Cu}(1: 3)$ alloy nanoparticles.

size of the alloy nanoparticles decreases. Slight broadening in the width of the desired peak occurred which points to the decrease in size of nanoparticles. The XRD signal also suggests that the sample consists of two kinds of metals, that is, $\mathrm{Au}$ and $\mathrm{Cu}$. However, $\mathrm{Cu}$ seems to be dispersed in the $\mathrm{Au}$ matrixes due to its smaller size. The atomic radius of $\mathrm{Cu}(0.14 \mathrm{~nm})$ is smaller than $\mathrm{Au}(0.18 \mathrm{~nm})$ [25]. Size of all the nanoparticles was calculated applying Debye Scherrer's equation:

$$
D=\frac{k \lambda}{\beta \cos \theta},
$$

where $k$ stands for particle shape factor and is taken as 0.899 for $\mathrm{Au}-\mathrm{Cu}, \lambda$ the wavelength of radiation, $\beta$ the calibrated half intensity width of the desired diffraction peak, and $\theta$ the half of peak position angle called Bragg's angle. The values of calculated average diameters of all the samples are listed in Table 5 showing a decrease with increase in mole fraction of $\mathrm{Cu}$.

3.4. Scanning Electron Microscopic (SEM) Studies. SEM images depicted in Figure 8 show that sizes of monometallic as well as bimetallic alloy nanoparticles are nonuniform. The observed mismatch in lattice spacing is due to very similar lattice parameters of $\mathrm{Au}$ and $\mathrm{Cu}$ [26]. The morphological structures of $\mathrm{Au}$ NPs, $\mathrm{Cu}$ NPs, and Au-Cu alloy nanoparticles prepared with various ratios can be seen in Figures 8(a)-8(e).

3.5. Transmission Electron Microscopic (TEM) Studies. TEM photographs of $\mathrm{Au}-\mathrm{Cu}$ bimetallic alloy nanoparticles at various ratios can be seen in Figures 9(a)-9(c). Au-Cu alloy particle size ranges from 80 to $65 \mathrm{~nm}$. A typical TEM image 


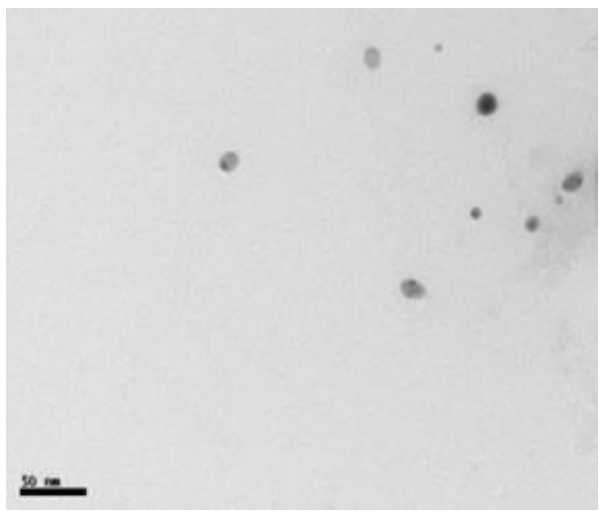

(a)

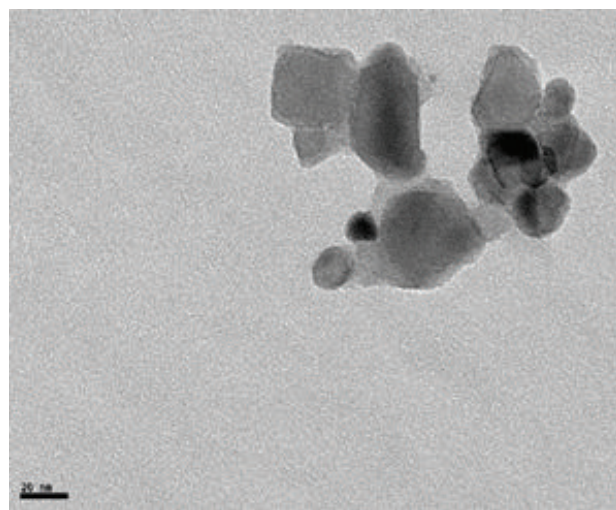

(b)

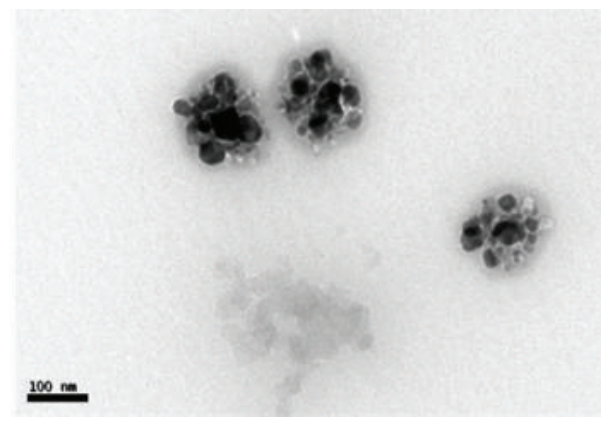

(c)

Figure 9: TEM images of (a) Au-Cu (1:1), (b) Au-Cu (1:2), and (c) Au-Cu (1:3) alloy nanoparticles.

TABLE 5: Size of nanoparticles calculated from SEM, TEM, and XRD.

\begin{tabular}{lcc}
\hline S. number & $\mathrm{Au}: \mathrm{Cu}$ & Average diameter/nm \\
\hline 1 & $3: 1$ & 80 \\
2 & $2: 1$ & 75 \\
3 & $1: 1$ & 70 \\
4 & $1: 2$ & 68 \\
5 & $1: 3$ & 65 \\
\hline
\end{tabular}

of $\mathrm{Au}-\mathrm{Cu}(1: 2)$ nanoparticles as shown in Figure 9(b) is nonspherical; however, shapes of $\mathrm{Au}-\mathrm{Cu}(1: 1)$ and $\mathrm{Au}-\mathrm{Cu}$ $(1: 3)$ nanoparticles are close to spherical shape as evidenced by Figures $9(\mathrm{a})$ and 9 (c). Interestingly, sizes shown by these images are the same as calculated from XRD. The size of nanoparticles evaluated from XRD as well as TEM can be seen in Table 5.

3.6. Conclusion. Chemical reduction process is the most simple and effective method for the synthesis of bimetallic $\mathrm{Au}-\mathrm{Cu}$ alloy nanoparticles. This method can also be used successfully for the synthesis of monometallic $\mathrm{Au}$ and $\mathrm{Cu}$ nanoparticles. UV-Visible spectroscopy is the sensitive technique used for the confirmation of the synthetic process. Change in the composition of nanoparticles was studied by UV-Visible spectroscopy and XRD. Morphology was studied by SEM and TEM. Quenching effect of $\mathrm{Cu}$ in $\mathrm{Au}-$ $\mathrm{Cu}$ alloy nanoparticles was revealed by the results obtained from fluorescence spectroscopy. SEM and TEM were applied for the calculation of average diameters and shape of the nanoparticles. EDS analysis revealed more than $90 \%$ purity of the synthesized $\mathrm{Au}-\mathrm{Cu}$ alloy nanoparticles. Nanoparticles were found nearly spherical in shape but modified slightly with change in composition of $\mathrm{Au}$ and $\mathrm{Cu}$. TEM results revealed that the shapes of $\mathrm{Au}-\mathrm{Cu}$ alloy in the ratio of $3: 1$ are more uniformly spherical. The applied synthetic method excels other methods owing to its higher efficiency and environmental friendliness. Moreover, it is easy to handle and does not require extensive instrumentation.

\section{Conflict of Interests}

The authors declare that there is no conflict of interests regarding the publication of this paper.

\section{Acknowledgments}

This work was jointly supported by the Chemistry Department of Quaid-i-Azam University, Islamabad, and National Center of Excellence in Physical Chemistry, University of Peshawar. The financial support of Higher Education Commission of Pakistan is also acknowledged.

\section{References}

[1] G. T. Wei, F. K. Liu, and C. R. C. Wang, "Shape separation of nanometer gold particles by size-exclusion chromatography," Analytical Chemistry, vol. 711, no. 999, pp. 2085-2091, 1999. 
[2] B. Ita, P. Murugavel, V. Ponnambalam, and A. R. Raju, "Magnetic properties of lanthanum orthoferrite fine powders prepared by different chemical routes," Journal of Chemical Sciences, vol. 115, no. 5-6, pp. 519-524, 2003.

[3] K. S. Shin, H. Kim, and K. Kim, "Novel fabrication and catalytic application of poly(ethylenimine)-stabilized gold-silver alloy nanoparticles," Journal of Nanoparticle Research, vol. 14, pp. 735-740, 2012.

[4] V. Abdelsayed, K. M. Saoud, and M. S. El-Shall, "Vapor phase synthesis and characterization of bimetallic alloy and supported nanoparticle catalysts," Journal of Nanoparticle Research, vol. 8, no. 3-4, pp. 519-531, 2006.

[5] L.-U. Rahman, R. Qureshi, A. Shah, and M. M. Yasinzai, "Synthesis and spectroscopic characterization of $\mathrm{Ag}-\mathrm{Cu}$ alloy nanoparticles prepared in various ratios," Comptes Rendus Chimie, vol. 15, no. 6, pp. 533-538, 2012.

[6] R. Huang, Y.-H. Wen, Z.-Z. Zhu, and S.-G. Sun, "Pt-Pd bimetallic catalysts: structural and thermal stabilities of core-shell and alloyed nanoparticles," The Journal of Physical Chemistry C, vol. 116, no. 15, pp. 8664-8671, 2012.

[7] J. Han, Y. Zahou, Y.-Q. Chai, L. Mao, Y.-L. Yuan, and R. Yuan, "Highly conducting gold nanoparticles-graphene nanohybrid films for ultrasensitive detection of carcinoembryonic antigen," Talanta, vol. 85, no. 1, pp. 130-135, 2011.

[8] J. Wang, J. Li, A. J. Baca et al., "Amplified voltammetric detection of DNA hybridization via oxidation of ferrocene caps on gold nanoparticle/streptavidin conjugates," Analytical Chemistry, vol. 75, no. 15, pp. 3941-3945, 2003.

[9] S. C. Banks, E. J. Knight, J. E. Dubach, and D. B. Lindenmayer, "Microhabitat heterogeneity influences offspring sex allocation and spatial kin structure in possums," Journal of Animal Ecology, vol. 77, no. 6, pp. 1250-1256, 2008.

[10] A. Alqudami, S. Annapoorni, Govind, and S. M. Shivaprasad, "Ag-Au alloy nanoparticles prepared by electro-exploding wire technique," Journal of Nanoparticle Research, vol. 10, no. 6, pp. 1027-1036, 2008.

[11] B. Delley, "From molecules to solids with the DMol3 approach," Journal of Chemical Physics, vol. 113, no. 18, pp. 7756-7764, 2000.

[12] M. J. Yacam, J. A. Ascencio, and H. B. Liu, "Structure shape and stability of nanometric sized particles," Journal of Vacuum Science \& Technology B, vol. 19, pp. 1091-1103, 2001.

[13] H. B. Liu, J. A. Ascencio, M. Perez-Alvarez, and M. J. Yacaman, "Melting behavior of nanometer sized gold isomers," Surface Science, vol. 491, no. 1-2, pp. 88-98, 2001.

[14] S. K. Shaikhutdinov, R. Meyer, M. Naschitzki, M. Bäumer, and H.-J. Freund, "Size and support effects for CO adsorption on gold model catalysts," Catalysis Letters, vol. 86, no. 4, pp. 211219, 2003.

[15] E. Sawosz and M. Grodzik, "The influence of silver nanoparticles on chicken embryo development and bursa of Fabricius morphology," Journal of Animal and Feed Sciences, vol. 15, supplement 1, pp. 111-114, 2006.

[16] H. Cai, N. Zhu, Y. Jiang, P. He, and Y. Fang, “Cu@Au alloy nanoparticle as oligonucleotides labels for electrochemical stripping detection of DNA hybridization," Biosensors and Bioelectronics, vol. 18, no. 11, pp. 1311-1319, 2003.

[17] H. A. Esfahani, L. Wang, Y. Nemoto, and Y. Yamauchi, "Synthesis of bimetallic Au@Pt nanoparticles with Au core and nanostructured Pt shell toward highly active electrocatalysts," Chemistry of Materials, vol. 22, no. 23, pp. 6310-6318, 2010.
[18] L. Wang, Y. Nemoto, and Y. Yamauchi, "Direct synthesis of spatially-controlled Pt-on-Pd bimetallic nanodendrites with superior electrocatalytic activity," Journal of the American Chemical Society, vol. 133, no. 25, pp. 9674-9677, 2011.

[19] Y.-H. Wen, Y. Zhang, J.-C. Zheng, Z.-Z. Zhu, and S.-G. Sun, "Orientation-dependent structural transition and melting of $\mathrm{Au}$ nanowires," Journal of Physical Chemistry C, vol. 113, no. 48, pp. 20611-20617, 2009.

[20] G. R. Souza, D. R. Christianson, F. I. Staquicini et al., "Networks of gold nanoparticles and bacteriophage as biological sensors and cell-targeting agents," Proceedings of the National Academy of Sciences of the United States of America, vol. 103, no. 5, pp. 1215-1220, 2006.

[21] T. A. Taton, C. A. Mirkin, and R. L. Letsinger, "Scanometric DNA array detection with nanoparticle probes," Science, vol. 289, no. 5485, pp. 1757-1760, 2000.

[22] X. Liu, A. Wang, X. Wang, C. Y. Mou, and T. Zhang, "Au$\mathrm{Cu}$ Alloy nanoparticles confined in SBA-15 as a highly efficient catalyst for CO oxidation," Chemical Communications, no. 27, pp. 3187-3189, 2008.

[23] P. Lisowski, M. Pierzchal, J. Goscik, C. S. Pareek, and L. Zwierzchowski, "Evaluation of reference genes for studies of gene expression in the bovine liver, kidney, pituitary, and thyroid," Journal of Applied Genetics, vol. 49, no. 4, pp. 367-372, 2008.

[24] Y. S. Kim, J. S. Kim, H. S. Cho et al., “Twenty-eight-day oral toxicity, genotoxicity, and gender-related tissue distribution of silver nanoparticles in Sprague-Dawley rats," Inhalation Toxicology, vol. 20, no. 6, pp. 575-583, 2008.

[25] J. F. Sanchez-Ramirez, C. Vazquez-Lopez, and U. Pal, "Preparation and optical absorption of colloidal dispersion of $\mathrm{Au} / \mathrm{Cu}$ nanoparticles," Superficies y Vacio, vol. 15, pp. 16-18, 2002.

[26] A. Shah, L.-U. Latif-Ur-Rahman, R. Qureshi, and Z.-U. ZiaUr-Rehman, "Synthesis, characterization and applications of bimetallic (Au-Ag, Au-Pt, Au-Ru) alloy nanoparticles," Reviews on Advanced Materials Science, vol. 30, no. 2, pp. 133-149, 2012. 

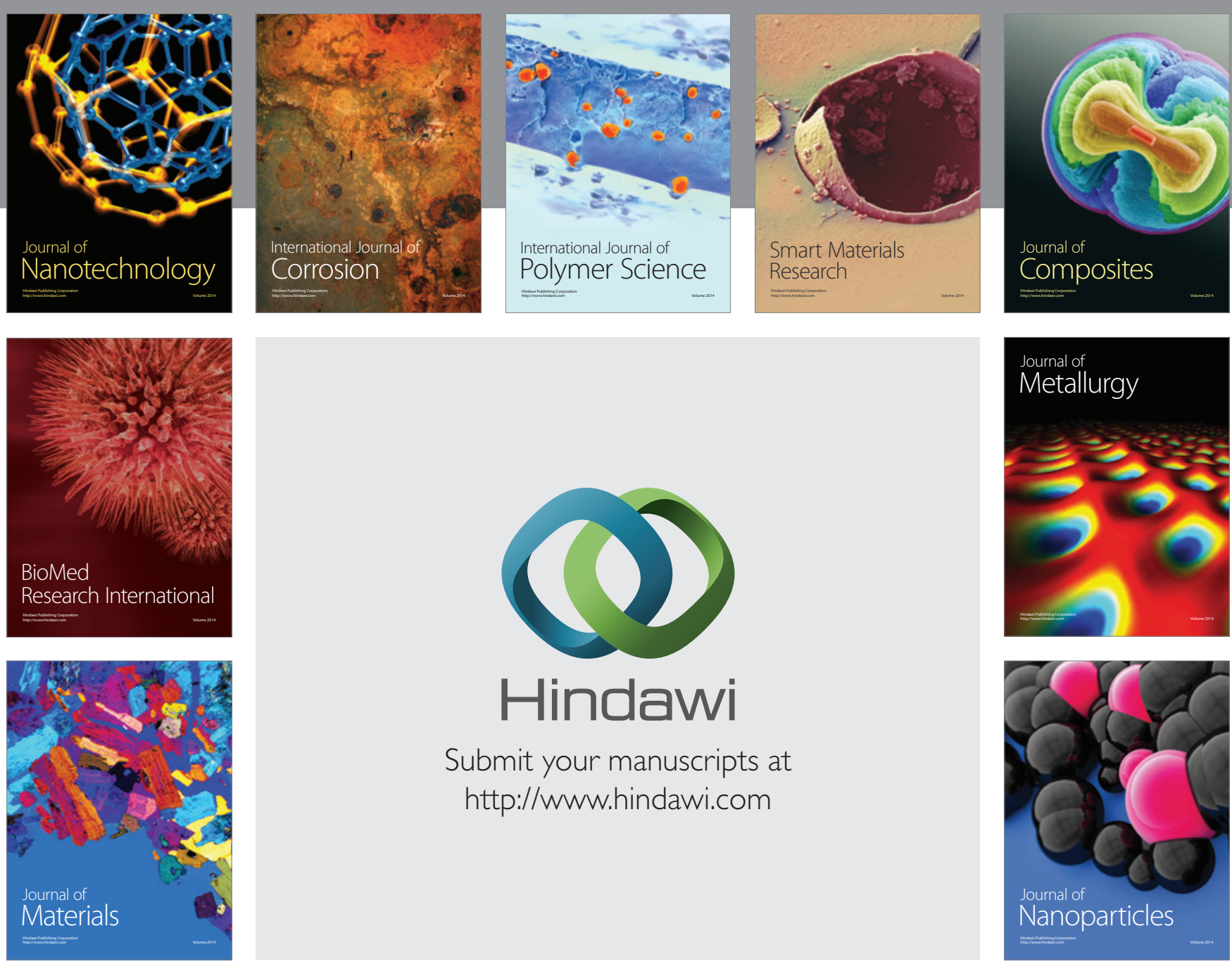

Submit your manuscripts at http://www.hindawi.com
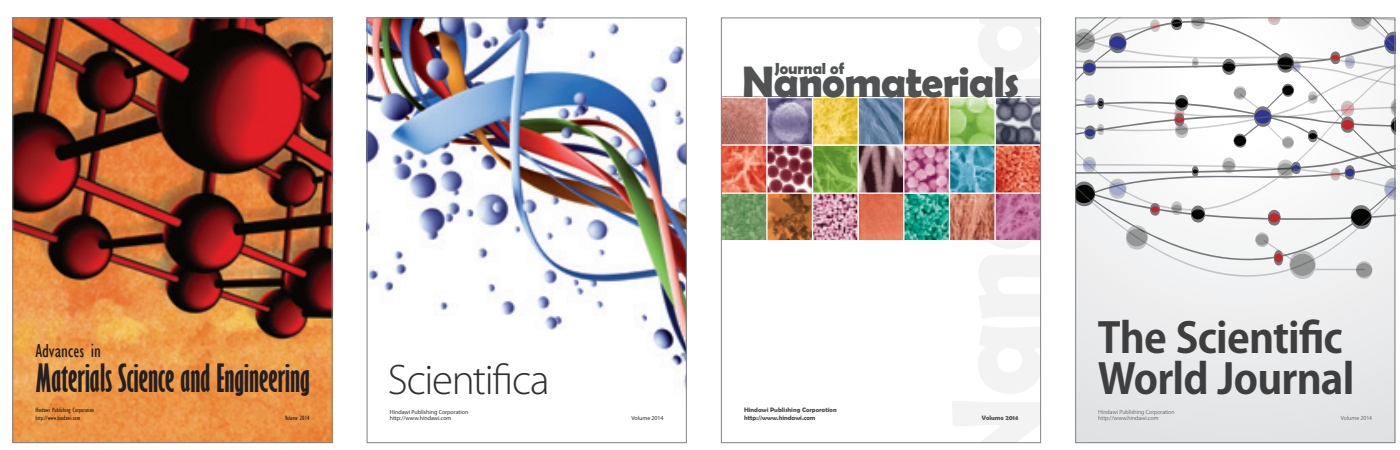

\section{The Scientific World Journal}
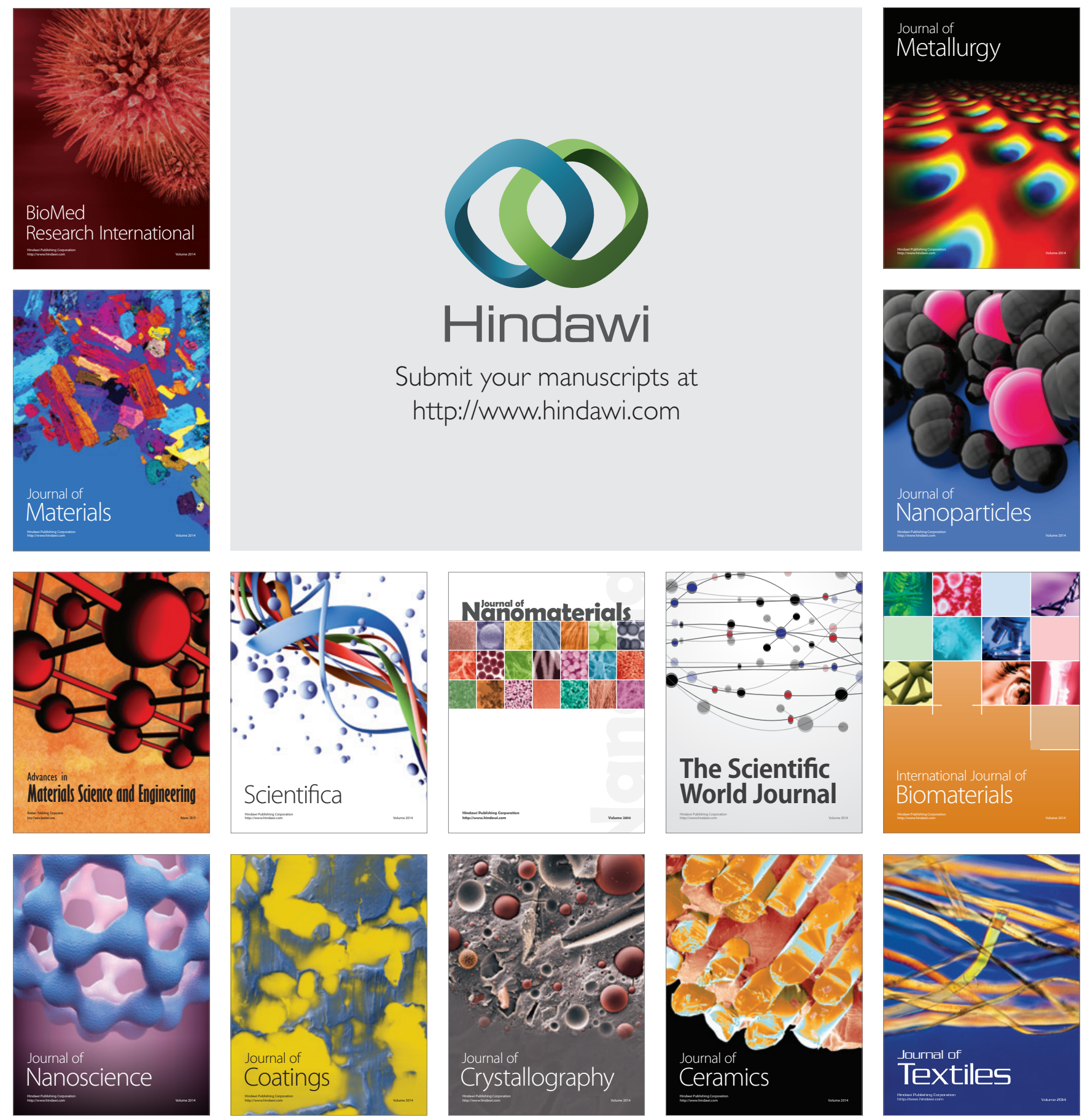